\title{
Novel nanoliposomes alleviate contrast-induced acute kidney injury in New Zealand rabbits by mediating inflammatory response
}

\author{
Hong Zhang ${ }^{1 \#}$, Peng Zhang ${ }^{1 \#}$, Xue Zhang ${ }^{2}$, Yanqiu Song ${ }^{3}$, Zhican Zeng' ${ }^{2}$ Xiaofeng Fu ${ }^{2}$, Han Fu ${ }^{2}$, \\ Qin Qin ${ }^{1}$, Naikuan Fu' ${ }^{1}$ Zhigang Guo ${ }^{1 \wedge}$ \\ ${ }^{1}$ Department of Cardiology, Tianjin Chest Hospital, Tianjin, China; ${ }^{2}$ Graduate School of Tianjin Medical University, Tianjin, China; ${ }^{3}$ Institute of \\ Cardiovascular Disease, Tianjin Chest Hospital, Tianjin, China \\ Contributions: (I) Conception and design: Z Guo, N Fu; (II) Administrative support: None; (III) Provision of study materials or patients: None; (IV) \\ Collection and assembly of data: Y Song, Q Qin; (V) Data analysis and interpretation: X Zhang, Z Zeng, X Fu, H Zhang; (VI) Manuscript writing: \\ All authors; (VII) Final approval of manuscript: All authors. \\ \#These authors contributed equally to this work. \\ Correspondence to: Zhigang Guo, PhD; Naikuan Fu, PhD. Tianjin Chest Hospital, No. 261, Taierzhuang South Road, Jinnan District, Tianjin 300222, \\ China. Email: guozhigangtjch@163.com; cdrfnk@163.com.
}

\begin{abstract}
Background: The purpose of the research was to investigate the preventive effect of nanoliposomes on contrast-induced nephropathy (CIN) in New Zealand rabbits and to provide a theoretical basis for clinically effective prevention and treatment of CIN and the development of new contrast agents.

Methods: A total of $48 \mathrm{New}$ Zealand rabbits were divided into four groups randomly, there were 12 rabbits in eacj group: (I) control group; (II) contrast group; (III) hydration prevention group; and (IV) nanoliposome group. The changes of serum creatinine (SCr) and blood urea nitrogen (BUN) were messured before and after injection of iopromide. Enzyme-linked immunosorbent assay (ELISA) was used to detect inflammatory and oxidative stress indexes, including neutrophil gelatinase-associated lipoprotein (NGAL), tumor necrosis factor- $\alpha(\mathrm{TNF}-\alpha)$, superoxide dismutase (SOD), and malondialdehyde (MDA). Twenty-four hours after injection of the contrast medium, the rabbits were killed and the pathological changes were observed under an electron microscope.

Results: There were statistical significances in $\mathrm{sCr}$ and BUN values among the four groups at both 8 hours and 24 hours after injection of the contrast medium. Serum NGAL and TNF- $\alpha$ levels were also significantly different among the four groups $(\mathrm{P}<0.05) 24$ hours after injection of the contrast medium. The incidence rate of CIN in each group was statistically significant. Nanoliposomes had obvious advantages over hydration prevention in NGAL and TNF- $\alpha$ levels.
\end{abstract}

Conclusions: Nanoliposomes can prevent the occurrence of CIN and reduce the damage of contrast agent to the kidney by reducing inflammatory reaction.

Keywords: Nanoliposomes; inflammatory; contrast agent; contrast-induced nephropathy

Submitted Jun 09, 2021. Accepted for publication Jul 22, 2021.

doi: 10.21037/atm-21-3201

View this article at: https://dx.doi.org/10.21037/atm-21-3201

\section{Introduction}

Contrast-induced acute kidney injury (CIAKI) occurs when $\mathrm{SCr}$ increases more than $25 \%$, or reaches modulus of greater than $44.2 \mu \mathrm{mol} / \mathrm{L}$, within 1-3 days following the injection of a contrast agent. (1). Dosage of contrast agent, diabetes, old age and previous chronic renal insufficiency are the close risk factors that affect the occurrence and

\footnotetext{
$\wedge$ ORCID: 0000-0001-9432-6535.
} 
development of CIAKI. CIAKI is the chief harmful event after iodine contrast agent injection, with an incidence of $10-30 \%$. It is the third major cause of disease in hospitalized patients, after drug-induced damage and ischemic damage. Researches have indicated that many harmful results, including death, cardiac complications, and dialysis, are closely linked to CIN. The morbidity of CIN aggects hospitalization time, short- and long-term incidence rates, and mortality $(2,3)$. Hence, preoperative interposion is very significant. Hydration therapy is the widely used and the lowest cost method to prevent CIN. Rehydration can increase effective circulating blood volime, and increse renal perfusion.

Many risk factors can promote the occurrence of CIN. For example, percutaneous coronary intervention (PCI), which is increasing in patients over 75 and in emergency department admissions, is a significant factor in the development of CIN (4). However, the most important risk factor for CIN is impairment of basic renal function, such as stage IV and $\mathrm{V}$ chronic kidney disease (CKD), which has a risk of CIN onset more than 3 times higher than that of patients with normal renal function $(5,6)$. However, there is no standard acute kidney injury treatment in clinic.

A nanoliposome is a type of lipid microcapsule structure (7), which is initially used as tumor adjuvant delivery systems. Nanoliposomes are much smaller in size than ordinary liposomes and have a high degree of deformability. The conductivity, stability, and adhesion if nanoliposomes in cell fluid or other body fluids offer great superiorities over ordinary liposomes (8-10). Further, nanoliposomes have no biological toxicity or allergens (11). In the treatment of acute kidney injury, nanoliposomes can protect the stability of mitochondrial transmembrane potential of renal cells by reducing the apoptosis injury of kidney and affecting the metabolism of mitochondria. This study aimed to investigate the effect of nanoliposomes on preventing and treating CIN in New Zealand rabbit CIN model, and provide a theoretical basis for clinically effective prevention and treatment of CIN and the development of a new contrast agent. We present the following article in accordance with the ARRIVE reporting checklist (available at https://dx.doi.org/10.21037/atm-21-3201).

\section{Methods}

\section{Use of animals}

Experiments were performed under a project license (No.:
2020YS-047-01) granted by institutional ethics board of Tianjin Chest Hospital, in compliance with Chinese national guidelines for the care and use of animals. A protocol was prepared before the study without registration.

\section{Construction of animal model}

A total of 48 New Zealand rabbits weighing about $2 \mathrm{~kg}$, raising at $18-25^{\circ} \mathrm{C}$ and fed and drank freely, were randomly divided into four groups by random number table, with 12 rabbits in each group. The control group was intravenously injected with normal saline $(24 \mathrm{~mL} / \mathrm{kg})$ (Guizhou Baite Pharmaceutical Co., Ltd., Guiyang, China); the contrast group was intravenously injected with the contrast agent iopromide $(24 \mathrm{~mL} / \mathrm{kg}$ ) (Bayer, Leverkusen, Germany); the hydration group was intravenously injected with the contrast agent iopromide $(24 \mathrm{~mL} / \mathrm{kg})$ and normal saline $(24 \mathrm{~mL} / \mathrm{kg})$; and the nanoliposome group was intravenously injected with the contrast agent iopromide $(24 \mathrm{~mL} / \mathrm{kg})$ and nanoliposomes $(2 \mathrm{~mL} / \mathrm{kg})$ (Shunna Technology Co., Ltd, Shanghai, China). All authors were aware of the group allocation.

The rabbits were anesthetized by an intraperitoneal injection of $3 \%$ pentobarbital. At the prescribed time intervals, the contrast agent, saline and nanoliposomes were injected into the auricular vein using an indwelling needle. Gauze was used to compress the auricular vein to stop bleeding until hemostasis occurred. Blood samples were drawn within 24 hours after the injection to detect $\mathrm{sCr}$ level.

The rabbits were killed 24 hours after the injection and the left kidney was cut obliquely about $1.5-2 \mathrm{~cm}$ outward and downward. The cortex was washed with $4{ }^{\circ} \mathrm{C}$ buffer solution and then put into a container containing $4{ }^{\circ} \mathrm{C}$ fixative solution ( $2.5 \%$ glutaraldehyde). Next, the cortex was cut into several $1 \mathrm{~mm}^{3}$ cubes, and the amount of renal cortex was cleaned and dried with saline, and weighed and saved at $-80^{\circ} \mathrm{C}$ for further use.

\section{Determination of renal function}

The renal function indexes of SCr and BUN were surveyed before and after injection of iopromide. $\mathrm{SCr}$ and $\mathrm{BUN}$ levels were tested using a TBA-120FR biochemical analyzer (Toshiba Co., Tokyo, Japan). A judgement of CIN was described as the increase of SCr by more than $25 \%$ compared with the baseline following the injection of contrast agent. 


\section{ELISA assay}

Inflammatory and oxidative stress indexes, including tumor necrosis factor- $\alpha$ (TNF- $\alpha$ ), superoxide dismutase (SOD), neutrophil gelatinase-associated lipoprotein (NGAL), malondialdehyde (MDA), and other indicators were detected using an enzyme-linked immunosorbent assay (ELISA) (Elixir Canada Medicine Company Ltd., Vancouver, Canada), according to the manufacturer's protocol. First, each well was coated with $100 \mu \mathrm{L}$ of standard solution. Specimens and controls were placed into the appropriate wells. To avoid potential microbial and chemical contamination, $50 \mu \mathrm{L}$ of enzyme conjugate was added to each well and the microwells were rinsed and lightly brushed with distilled or deionized water 5 times. Next, $300 \mu \mathrm{L}$ of the diluted wash concentrate was added to all wells and the plate was inverted and tapped after the final wash to remove any residual fluid. The same procedural sequence was maintained for aspiration, with $50 \mu \mathrm{L}$ of Chromogen A and Chromogen B reagent added to each well. The absorbance was read within 10 minutes using a micro titrator at $450 \mathrm{~nm}$.

\section{Pathological examination}

The ultrastructural changes of mitochondria, endoplasmic reticulum and endothelial cells were surveyed using a HITACHI H800 electron microscope (HITACHI Ltd., Tokyo, Japan). The electron microscope examination was performed with technical support provided by Tianjin Institute of Biotechnology, Chinese Academy of Sciences.

\section{Statistical analysis}

Statistical analysis was done using IBM SPSS 20.0 software. The experimental data is expressed as mean \pm standard deviation (SD). Fisher's Least Significant Difference (LSD) test or Dunnett- $t$ test were applied between two groups and chi square test was used to analyze categorical variables. $\mathrm{P}<0.05$ was considered statistically significant.

\section{Results}

\section{Comparison of SCr and BUN in four groups}

At 8 hours after injection, $\mathrm{SCr}$ values were $178.00 \pm 72.63$ and $113.67 \pm 31.63(\mathrm{P}=0.001)$ for the contrast group and nanoliposome group, respectively, while 24 hours after injection, $\mathrm{SCr}$ values for the contrast and nanoliposome groups were $174.75 \pm 97.51$ and $90.42 \pm 17.22(\mathrm{P}<0.001)$, respectively. The SCr value for the contrast group was significantly higher than that for the nanoliposome group at both 8 and 24 hours after injection $(\mathrm{P}<0.05$, Figure 1A). At 8 and 24 hours after injection, the BUN for the contrast group was significantly higher than for the nanoliposome group (8 hours: $11.55 \pm 4.64$ vs. $7.93 \pm 2.67$, $\mathrm{P}=0.017 ; 24$ hours: $12.55 \pm 8.49$ vs. $5.92 \pm 2.43, \mathrm{P}=0.007$; Figure 1B).

\section{Determination of inflammatory and oxidative stress indexes}

Twenty-four hours after injecting the contrast medium, the NGAL and TNF- $\alpha$ levels in contrast group were significantly higher than the control group (Figure 2), indicating that the renal function of the rabbits in the contrast group had different degrees of inflammatory injury, causing renal function degeneration. The concentration of NGAL in the hydration group and nanoliposome group was significantly lower than those in the contrast group ( $42.06 \pm 22.19$ vs. $59.14 \pm 20.99, \mathrm{P}=0.046$ and $35.28 \pm 25.12$ vs. $59.14 \pm 20.99, \mathrm{P}=0.006$; Figure $2 A$ ), and the concentration of TNF- $\alpha$ in the nanoliposome group was significantly lower than in the contrast group $(28.43 \pm 17.16 v s .57 .01 \pm 20.45$, $\mathrm{P}=0.001$; Figure $2 B$ ), indicating that hydration with saline and the application of nanoliposomes played an important role by alleviating the inflammatory reaction and protecting renal function. After 8 hours following injection, the concentration of NGAL in the nanoliposome group was significantly lower than in the contrast group $(38.54 \pm 25.98$ vs. $62.32 \pm 21.69, \mathrm{P}=0.010$; Figure $2 A)$. The TNF- $\alpha$ concentration in hydration and nanoliposome groups was significantly lower than the contrast group $(47.57 \pm 28.34$ vs. $66.24 \pm 19.89, \mathrm{P}=0.039 ; 34.77 \pm 19.96$ vs. $66.24 \pm 19.89$, $\mathrm{P}=0.001$; Figure $2 B$ ). NGAL and TNF- $\alpha$ levels in the hydration group and nanoliposome group decreased at 2 hours compared with the contrast group, but there was no statistical significance $(\mathrm{P}>0.05$, Figure $2 A, 2 B)$. For $\mathrm{SOD}$ and MDA, no significant difference was found among the four groups at any of the time intervals (Figure 2C,2D). These findings suggested that inflammatory reaction is an important mechanism of CIN.

\section{Pathologic findings}

The incidence rates of CIN in the control, contrast, hydration, and nanoliposome groups were $0 \%(0 / 12), 67 \%$ (8/12), 50\% (6/12), and 25\% (3/12), respectively. There was significant difference among the four groups $(\mathrm{P}=0.002)$. For 


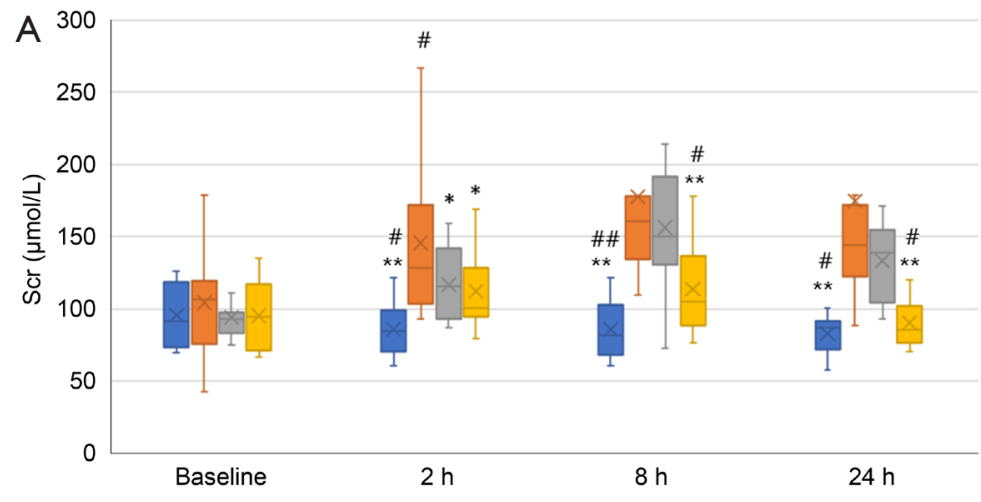

Control group

Contrast group

$\square$ Hydration group

Nanoliposome group

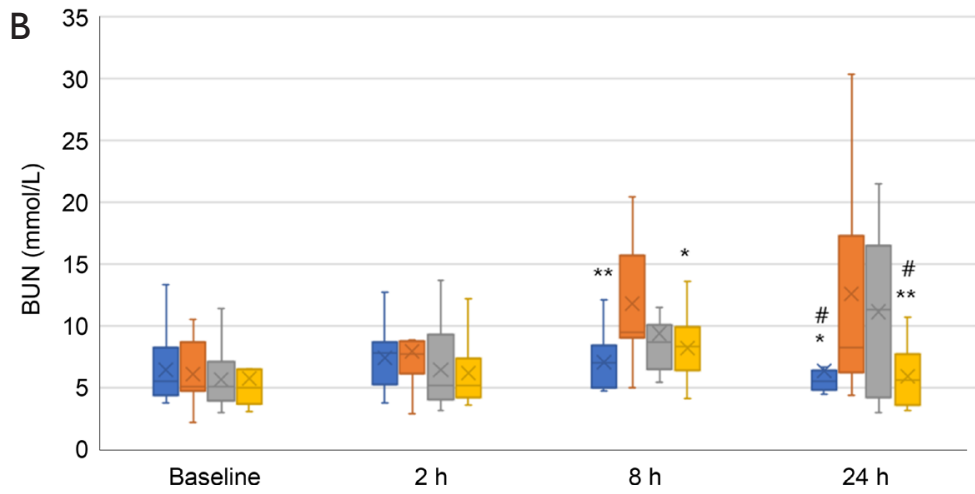

Control group

Contrast group

$\square$ Hydration group

$\square$ Nanoliposome group

Figure 1 Comparison of renal functions among four groups. (A) SCr values among four groups at different time intervals. (B) BUN values among four groups at different time intervals. Compared with the contrast group, ${ }^{*} \mathrm{P}<0.05 ;{ }^{* *} \mathrm{P}<0.01$. Compared with the hydration group, ${ }^{\#} \mathrm{P}<0.05 ;{ }^{\#} \mathrm{P}<0.01$. SCr, serum creatinine; BUN, blood urea nitrogen.

pairwise comparisons between groups, the incidence rate of contrast $v s$. nanoliposome groups $(\mathrm{P}=0.007)$, contrast $v$ s. control groups $(\mathrm{P}=0.002)$, and hydration $v$ s. nanoliposome groups $(\mathrm{P}=0.025)$ showed statistical difference.

The kidney specimens of the CIN animals were observed under an electron microscope. Normal kidney tissue and renal tubule structure were observed in the control group (Figure $3 A$ ). The ultrastructural changes found in the contrast group included swelling of mitochondria, disorder of boundary cristae, microvilli, and apoptotic cells in the lumen (Figure 3B). In the hydration group and nanoliposome group, the ultrastructure showed that the mitochondria of renal tubular epithelial cells swelled obviously, mitotic swelling of mitochondria was light, the structure of the internal boundary ridge was normal, with a few broken areas, and a few tissue cells were apoptotic, without nuclear pyknosis (Figure 3C,3D).

\section{Discussion}

In recent years, a large number of studies have shown that inflammatory mediating reaction plays an important role in the occurrence and development of renal function damage and deterioration $(12,13)$. CIN can be considered the renal function damage caused by contrast media. After the contrast agent enters the organism, it can stimulate the proinflammatory factor reaction in vivo, directly causing kidney damage to the renal tubular epithelium and leading to an increased risk of CIN (14). Despite the continuous improvement of contrast media, the incidence of CIN is still rising, and the mortality rate is also rising. So far, the pathogenesis of CIN has not been fully elucidated. It may be related to the imbalance of vasodilation and contraction of renal medulla caused by contrast agent, direct toxicity of contrast agent to kidney, inflammatory reaction and apoptosis. NGAL and TNF- $\alpha$ are highly sensitive markers which can indicate the inflammatory state of the body.

NGAL is a relatively small protein in the lipoprotein family, which was first found in human neutrophils. NGAL is the response of nephron to renal tubular epithelial injury $(15,16)$. In AKI, elevated NGAL levels have been confirmed. NGAL is very stable, so it can be easily detected 

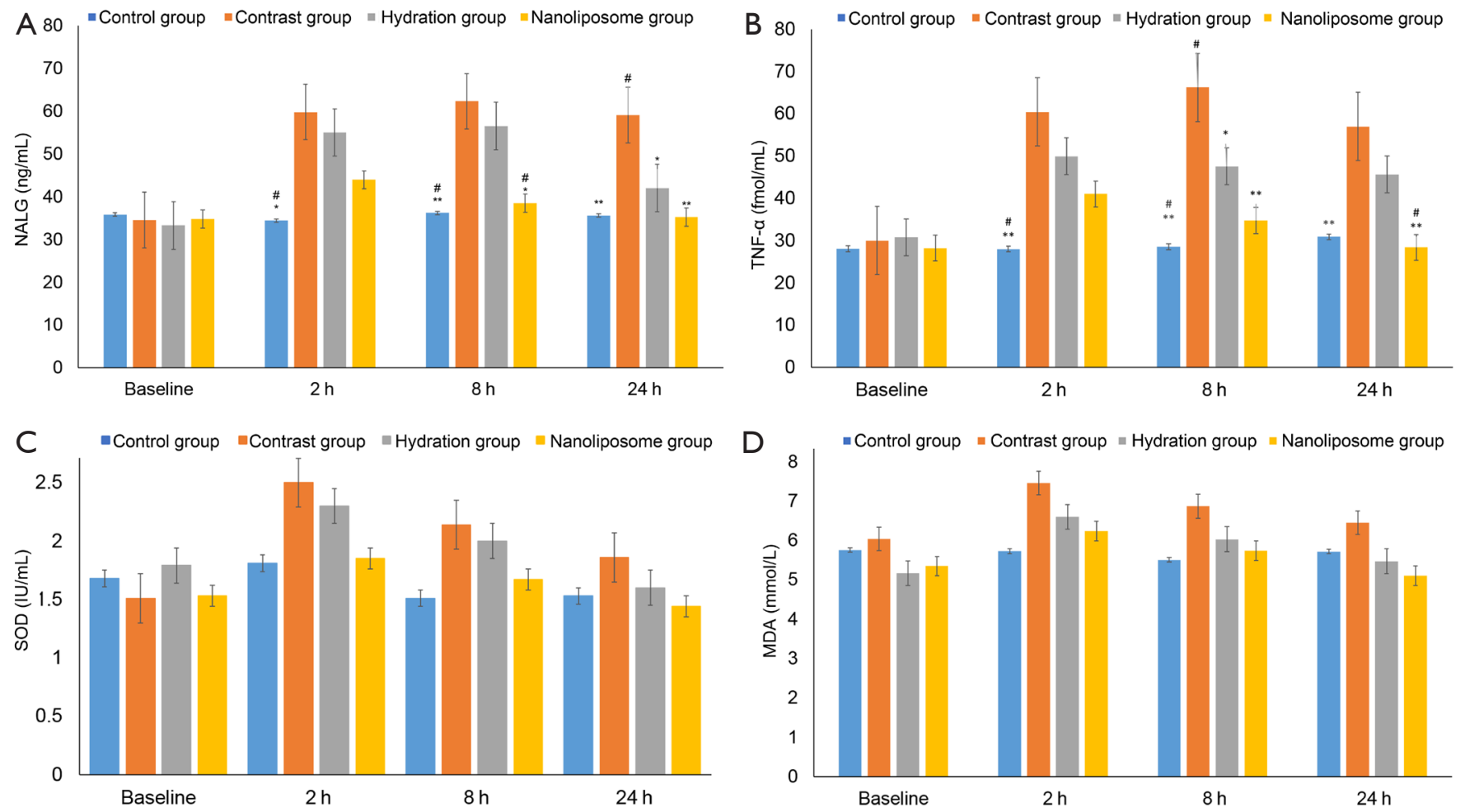

Figure 2 Comparison of inflammatory and oxidative stress indexes among four groups. (A) NGAL concentrations among four groups at different time intervals. (B) TNF- $\alpha$ concentrations among four groups at different time intervals. (C) SOD concentrations among four groups at different time intervals. (D) MDA concentrations among four groups at different time intervals. Compared with the contrast group, ${ }^{*} \mathrm{P}<0.05 ;{ }^{*} \mathrm{P}<0.01$. Compared with the hydration group, ${ }^{*} \mathrm{P}<0.05$. NGAL, neutrophil gelatinase associated lipoprotein; TNF- $\alpha$, tumor necrosis factor- $\alpha$; SOD, superoxide dismutase; MDA, malondialdehyde.

in serum. Under normal circumstances, NGAL expression is low in many tissues (lung, kidney, large intestine, and stomach). Apoptosis of epithelial cells with high expression level can induce NGAL-expression cell damage $(17,18)$. Recent evidence has revealed that NGAL is elevated in CKD regardless of etiology and elevated NGAL levels can predict the progression of CKD $(19,20)$. Early diagnosis and treatment strategies are needed in clinical practice to predict the progression of disease. Since SCr levels cannot immediately identify or predict the progression of renal damage, it is necessary to find novel early markers. NGAL was synthesized as a marker of kidney injury. Previous studies have found that NGAL level has a significant correlation with the severity of renal damage and might be an ideal biomarker for early renal damage in patients with CKD (21). Mitnefes et al. (22) found that the correlation between plasma NGAL and the estimated glomerular filtration rate (eGFR) was better than that of SCr and cystatin $\mathrm{C}$ with eGFR. Recent evidence suggests that
NGAL may even be involved in CKD (23). Cross-sectional studies of autosomal dominant polycystic disease and IgA nephropathy illustrated that urine and serum NGAL might affect renal function in nephropathy, glomerulonephritis, pediatric lupus nephritis, and chronic kidney diseases (24). After 2 years of follow up, Shen et al. (20) found that the severity of renal damage was closely related to the deterioration of renal function in 92 patients with stage 2-4 CKD caused by primary chronic glomerulonephritis.

TNF- $\alpha$ is mainly composed of monocytes and macrophages. Other cells, such as lymphocytes, vascular endothelial cells and fibroblasts can also produce TNF- $\alpha$ (25). TNF- $\alpha$ activates a variety of signaling pathways by binding to receptors, including c-Jun $\mathrm{N}$-terminal kinase (JNK), the NADPH oxidase activation pathway, and nuclear factor kappa B (NF-кB), etc. (26,27). In endothelial cells, TNF- $\alpha$ has been shown to inhibit the expression of endothelial nitric oxide synthase (eNOS) (28), thus increasing the activation of the NF- $\mathrm{KB}$ pathway through 

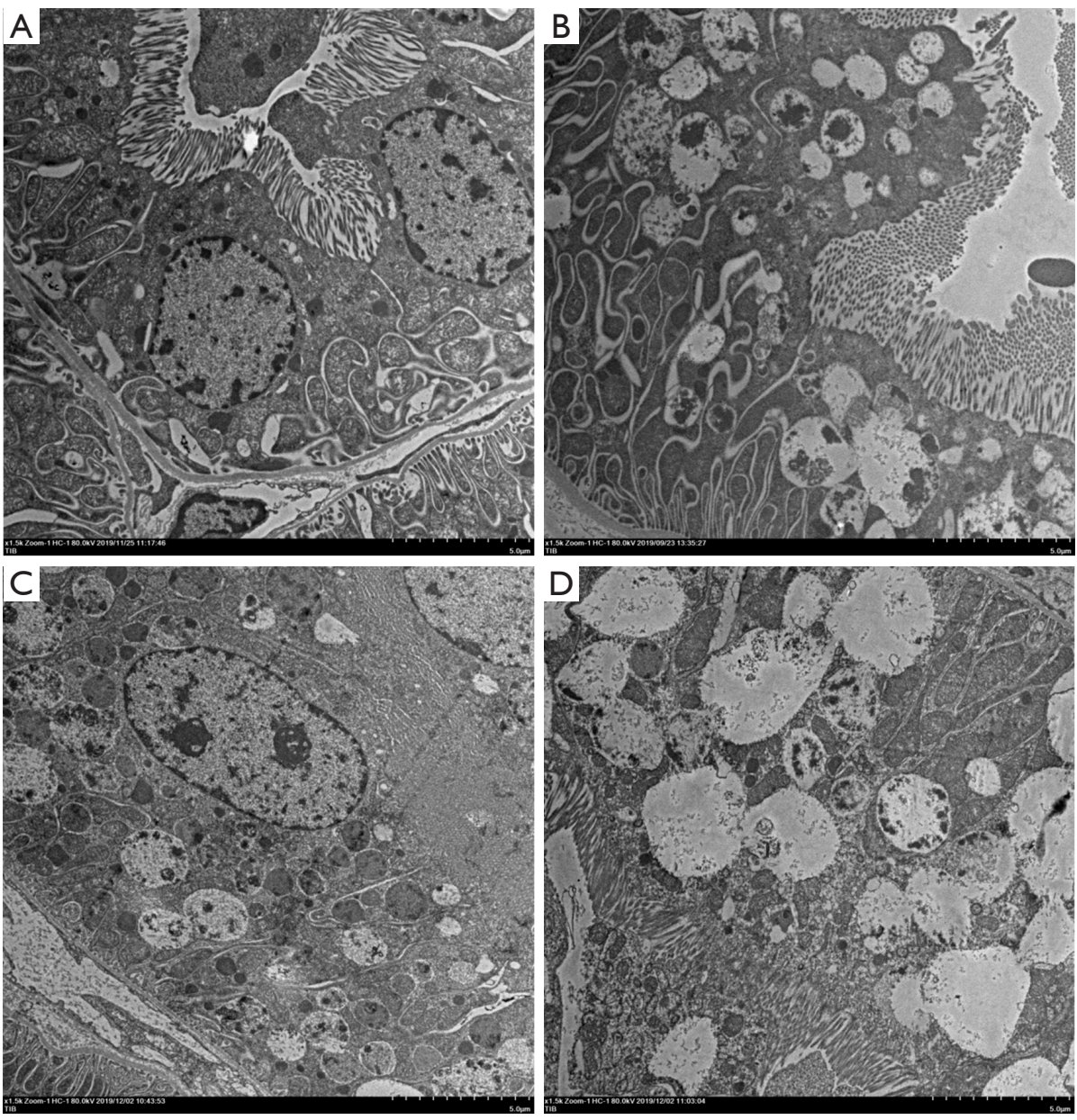

Figure 3 Pathologic findings in different groups of New Zealand rabbits. (A) Renal ultrastructure of New Zealand rabbits in control group; (B) renal ultrastructure of New Zealand rabbits in contrast group; (C) renal ultrastructure of New Zealand rabbits in hydration group; (D) renal ultrastructure of New Zealand rabbits in nanoliposome group.

the instability of eNOS mRNA (29). In endothelial and vascular smooth muscle cells, TNF- $\alpha$ activates NADPH oxidase to induce inflammatory oxidation (30). A growing body of evidence has shown that TNF- $\alpha$ shows an increasingly significant role in the diagnosis and treatment of macrovascular and metabolic inflammatory diseases such as obesity, diabetic metabolic syndrome, myocardial ischemia, and rheumatoid arthritis (31-33). We have previously demonstrated severe endothelial dysfunction and activationrelated organ damage in salt-sensitive hypertension and that the NF- $\kappa \mathrm{B}$ inflammatory pathway is related to the expression of TNF- $\alpha$ in vascular proliferation $(34,35)$. Further, Elmarakby et al. (36) revealed the inhibitory effect of TNF- $\alpha$ on renal injury in salt-induced hypertensive rats.

In this study, nanoliposomes can mix together with the renal cell membrane, postpone the apoptosis of organelles, and finally lessen kidney damage. The outcomes supply a new way for the prevention of CIN, and offer a theoretical basis for the research of new contrast agents. However, results of this paper are limited to the laboratory scale, and large-scale clinical studies are necessary to prove the clinical usefulness of nanoliposomes, to effectively reduce the happening of renal events after PCI, and better the shortand long-term final result of patients.

In conclusion, we successfully established a New Zealand rabbit model of CIN and confirmed that the occurrence of CIN might be related to inflammatory reaction. We showed that nanoliposomes can reduce the occurrence of CIN and the damage of contrast agent to the kidney. These findings could support the development of new options for clinical 
practice and treatment to reduce the incidence of CIN.

\section{Acknowledgments}

Funding: This work was supported by a grant from the Tianjin Haihe medical scholar program.

\section{Footnote}

Reporting Checklist: The authors have completed the ARRIVE reporting checklist. Available at https://dx.doi. org/10.21037/atm-21-3201

Data Sharing Statement: Available at https://dx.doi. org/10.21037/atm-21-3201

Conflicts of Interest: All authors have completed the ICMJE uniform disclosure form (available at https://dx.doi. org/10.21037/atm-21-3201). The authors have no conflicts of interest to declare.

Ethical Statement: The authors are accountable for all aspects of the work in ensuring that questions related to the accuracy or integrity of any part of the work are appropriately investigated and resolved. Experiments were performed under a project license (No.: 2020YS-04701) granted by institutional ethics board of Tianjin Chest Hospital, in compliance with Chinese national guidelines for the care and use of animals. A protocol was prepared before the study without registration.

Open Access Statement: This is an Open Access article distributed in accordance with the Creative Commons Attribution-NonCommercial-NoDerivs 4.0 International License (CC BY-NC-ND 4.0), which permits the noncommercial replication and distribution of the article with the strict proviso that no changes or edits are made and the original work is properly cited (including links to both the formal publication through the relevant DOI and the license). See: https://creativecommons.org/licenses/by-nc-nd/4.0/.

\section{References}

1. Rihal CS, Textor SC, Grill DE, et al. Incidence and prognostic importance of acute renal failure after percutaneous coronary intervention. Circulation 2002;105:2259-64.

2. Toprak O. Risk markers for contrast-induced nephropathy.
Am J Med Sci 2007;334:283-90.

3. Zuo P, Li Y, Zuo Z, Wang X, et al. Glycemic variability as predictor of contrast-induced nephropathy in diabetic patients with acute myocardial infarction undergoing percutaneous coronary intervention. Ann Transl Med 2020;8:1505.

4. Geenen RW, Kingma HJ, van der Molen AJ. Contrastinduced nephropathy: pharmacology, pathophysiology and prevention. Insights Imaging 2013;4:811-20.

5. Jorgensen AL. Contrast-induced nephropathy: pathophysiology and preventive strategies. Crit Care Nurse 2013;33:37-46.

6. Heyman SN, Rosen S, Khamaisi M, et al. Reactive oxygen species and the pathogenesis of radiocontrast-induced nephropathy. Invest Radiol 2010;45:188-95.

7. Carr R, Weinstock IA, Sivaprasadarao A, et al. Synthetic ion channels via self-assembly: a route for embedding porous polyoxometalate nanocapsules in lipid bilayer membranes. Nano Lett 2008;8:3916-21.

8. Goldberg R, Klein J. Liposomes as lubricants: beyond drug delivery. Chem Phys Lipids 2012;165:374-81.

9. Faulk A, Weissig V, Elbayoumi T. Mitochondria-specific nano-emulsified therapy for myocardial protection against doxorubicin-induced cardiotoxicity. Methods Mol Biol 2013;991:99-112.

10. Yamada Y, Harashima H. Targeting the mitochondrial genome via a dual function MITO-Porter: evaluation of mtDNA levels and mitochondrial function. Methods Mol Biol 2015;1265:123-33.

11. Khalil IA, Kogure K, Futaki S, et al. Octaarginine-modified liposomes: enhanced cellular uptake and controlled intracellular trafficking. Int J Pharm 2008;354:39-48.

12. Jaber BL, Pereira BJ, Bonventre JV, et al. Polymorphism of host response genes: implications in the pathogenesis and treatment of acute renal failure. Kidney Int 2005;67:14-33.

13. Bonventre JV, Weinberg JM. Recent advances in the pathophysiology of ischemic acute renal failure. J Am Soc Nephrol 2003;14:2199-210.

14. Ramesh G, Reeves WB. TNF-alpha mediates chemokine and cytokine expression and renal injury in cisplatin nephrotoxicity. J Clin Invest 2002;110:835-42.

15. Bolignano D, Donato V, Coppolino G, et al. Neutrophil gelatinase-associated lipocalin (NGAL) as a marker of kidney damage. Am J Kidney Dis 2008;52:595-605.

16. Flo TH, Smith KD, Sato S, et al. Lipocalin 2 mediates an innate immune response to bacterial infection by sequestrating iron. Nature 2004;432:917-21.

17. Patel ML, Sachan R, Verma A, et al. Neutrophil 
gelatinase-associated lipocalin as a biomarker of disease progression in patients with chronic kidney disease. Indian J Nephrol 2016;26:125-30.

18. Sinna MM, Altaf FMN, Mosa OF. Serum and Urinary NGAL and Cystatin C Levels as Diagnostic Tools for Acute Kidney Injury and Chronic Kidney Disease: A Histobiochemical Comparative Study. Curr Pharm Des 2019;25:1122-33.

19. Gharishvandi F, Kazerouni F, Ghanei E, et al. Comparative assessment of neutrophil gelatinase-associated lipocalin (NGAL) and cystatin C as early biomarkers for early detection of renal failure in patients with hypertension. Iran Biomed J 2015;19:76-81.

20. Shen SJ, Hu ZX, Li QH, et al. Implications of the changes in serum neutrophil gelatinase-associated lipocalin and cystatin $\mathrm{C}$ in patients with chronic kidney disease. Nephrology (Carlton) 2014;19:129-35.

21. Xiang D, Zhang H, Bai J, et al. Clinical application of neutrophil gelatinase-associated lipocalin in the revised chronic kidney disease classification. Int J Clin Exp Pathol 2014;7:7172-81.

22. Mitsnefes MM, Kathman TS, Mishra J, et al. Serum neutrophil gelatinase-associated lipocalin as a marker of renal function in children with chronic kidney disease. Pediatr Nephrol 2007;22:101-8.

23. Malyszko J, Bachorzewska-Gajewska H, Sitniewska E, et al. Serum neutrophil gelatinase-associated lipocalin as a marker of renal function in non-diabetic patients with stage 2-4 chronic kidney disease. Ren Fail 2008;30:625-8.

24. Fassett RG, Venuthurupalli SK, Gobe GC, et al. Biomarkers in chronic kidney disease: a review. Kidney Int 2011;80:806-21.

25. McMaster WG, Kirabo A, Madhur MS, et al. Inflammation, immunity, and hypertensive end-organ damage. Circ Res 2015;116:1022-33.

26. Moe KT, Khairunnisa K, Yin NO, et al. Tumor necrosis factor- $\alpha$-induced nuclear factor-kappaB activation in human cardiomyocytes is mediated by NADPH oxidase. J Physiol Biochem 2014;70:769-79.

27. Miyoshi A, Koyama S, Sasagawa-Monden M, et al. JNK

Cite this article as: Zhang $\mathrm{H}$, Zhang $\mathrm{P}$, Zhang $\mathrm{X}$, Song $\mathrm{Y}$, Zeng Z, Fu X, Fu H, Qin Q, Fu N, Guo Z. Novel nanoliposomes alleviate contrast-induced acute kidney injury in New Zealand rabbits by mediating inflammatory response. Ann Transl Med 2021;9(15):1250. doi: 10.21037/atm-21-3201 and ATF4 as two important platforms for tumor necrosis factor- $\alpha$-stimulated shedding of receptor for advanced glycation end products. FASEB J 2019;33:3575-89.

28. Sun HX, Zeng DY, Li RT, et al. Essential role of microRNA-155 in regulating endothelium-dependent vasorelaxation by targeting endothelial nitric oxide synthase. Hypertension 2012;60:1407-14.

29. Yan S, Zhang X, Zheng H, et al. Clematichinenoside inhibits VCAM-1 and ICAM- 1 expression in TNF- $\alpha-$ treated endothelial cells via NADPH oxidase-dependent I $\kappa$ B kinase/NF- $\kappa$ B pathway. Free Radic Biol Med 2015;78:190-201.

30. Zhao W, Feng H, Guo S, et al. Danshenol A inhibits TNF- $\alpha$-induced expression of intercellular adhesion molecule-1 (ICAM-1) mediated by NOX4 in endothelial cells. Sci Rep 2017;7:12953.

31. Gao X, Belmadani S, Picchi A, et al. Tumor necrosis factor-alpha induces endothelial dysfunction in Lepr(db) mice. Circulation 2007;115:245-54.

32. Zhang H, Park Y, Wu J, et al. Role of TNF-alpha in vascular dysfunction. Clin Sci (Lond) 2009;116:219-30.

33. Pires PW, Girgla SS, Moreno G, et al. Tumor necrosis factor- $\alpha$ inhibition attenuates middle cerebral artery remodeling but increases cerebral ischemic damage in hypertensive rats. Am J Physiol Heart Circ Physiol 2014;307:H658-69.

34. Zhou MS, Schulman IH, Raij L. Role of angiotensin II and oxidative stress in vascular insulin resistance linked to hypertension. Am J Physiol Heart Circ Physiol 2009;296:H833-9.

35. Zhou MS, Schulman IH, Raij L. Vascular inflammation, insulin resistance, and endothelial dysfunction in saltsensitive hypertension: role of nuclear factor kappa B activation. J Hypertens 2010;28:527-35.

36. Elmarakby AA, Quigley JE, Imig JD, et al. TNF-alpha inhibition reduces renal injury in DOCA-salt hypertensive rats. Am J Physiol Regul Integr Comp Physiol 2008;294:R76-83.

(English Language Editor: A. Muijlwijk) 